\title{
Article
}

\section{Self-Assembly of Lamellar Clays to Hierarchical Microarrays} Jiang-Jen Lin, Yu-Min Chen, Wei-Cheng Tsai, and Chih-Wei Chiu

J. Phys. Chem. C, 2008, 112 (26), 9637-9643 • DOI: 10.1021/jp801733a • Publication Date (Web): 05 June 2008

Downloaded from http://pubs.acs.org on December 28, 2008

\section{More About This Article}

Additional resources and features associated with this article are available within the HTML version:

- Supporting Information

- $\quad$ Links to the 1 articles that cite this article, as of the time of this article download

- $\quad$ Access to high resolution figures

- $\quad$ Links to articles and content related to this article

- Copyright permission to reproduce figures and/or text from this article

\section{View the Full Text HTML}




\title{
Self-Assembly of Lamellar Clays to Hierarchical Microarrays
}

\author{
Jiang-Jen Lin,* Yu-Min Chen, Wei-Cheng Tsai, and Chih-Wei Chiu \\ Institute of Polymer Science and Engineering, National Taiwan University, Taipei 10617, Taiwan \\ Received: February 28, 2008; Revised Manuscript Received: April 15, 2008
}

\begin{abstract}
We uncover new self-assembled morphologies such as lengthy rods, dendrites, and rod-bundles from the lamellar clays. The unique formation of lengthy rod (ca. $0.3 \mu \mathrm{m}$ in diameter and up to $40 \mu \mathrm{m}$ in length), hierarchical rod-bundle (ca. $3 \mu \mathrm{m}$ in diameter) and dendrite-like arrays was observed using scanning electron microscopy (SEM), transmission electron microscopy (TEM), and atomic force microscopy (AFM). These microstructures were formed by self-piling the primary units of lamellar clay stacks that were intercalated with poly(oxypropylene)-amine salts (POP) within the interlayer spaces. Depending on the clay dimensions, the high-aspect-ratio mica $(300-500 \mathrm{~nm}$ for plate dimension) tends to form lengthy rods and rod-bundles, whereas montmorillonite (80-100 nm for average plates) often leads to less orderly dendrites. The selfassemblies, elucidated by TEM and AFM micrograms, may involve two piling directions of the primary stack units by face-to-face alignment and edge-to-edge POP interaction. These hierarchical microstructures with different morphologies are controllable by selecting the self-assembling procedures, such as direct water evaporation and toluene/water interfacial film formation.
\end{abstract}

\section{Introduction}

Self-organized nanostructures are ubiquitous in naturally occurring materials, including biomaterials, ${ }^{1}$ inorganic clays ${ }^{2}$ and biominerals such as shells, bones, and nacres. ${ }^{3-5}$ Recently, the development of a bottom-up self-assembling technique for fabricating devices on a nanometer scale have found wide applications, including electronic, ${ }^{6}$ magnetic, ${ }^{7}$ and photonic materials ${ }^{8}$ and quantum dots. ${ }^{9}$ The synthesis of these nanomaterials generally involves organic surfactants or amphiphilic copolymers as templates in directing the formation of hierarchical structures. Various geometric shapes such as nanospheres, ${ }^{10}$ -fibers, ${ }^{11}$-rings, ${ }^{12}$ and -filaments, ${ }^{13}$ as few examples, are documented. In general, these bottom-up syntheses are driven by the noncovalent bonding forces-electrostatic charge attraction, hydrogen bonding, van der Waals forces, and hydrophobic interactions - in a complimentary manner.

Among the most abundant minerals, the smectite clays are known for their layered structures of plate shape and diversified applications, including catalysts, absorbents, and polymer/clay nanocomposites. ${ }^{14-17}$ It was reported that there existed a strong attracting force among the high-aspect-ratio plates in forming ordered orientation and exhibiting a liquid crystal behavior. ${ }^{18}$ However, their self-aligning property to form orderly arrays has yet to be widely recognized, perhaps due to the lacking of homogeneity in their dimensional size and charge. In our recent developments on the organic modification to clay, the problem of inhomogeneity has been resolved to some extent by intercalating polymeric surfactants and, consequently, expanding the silicate interlayer distance from $1.2 \mathrm{~nm}$ to as high as $9 \mathrm{~nm}$ to form more orderly structures. As a result, the organically modified clays are found to have a high regularity of XRD Bragg's pattern. ${ }^{19,20}$ For example, the commonly utilized montmorillonite clay has an average of $8-10$ plate stacks as the primary units with a widely dispersed plate dimension ranging from $80-100 \mathrm{~nm}$ wide and $1 \mathrm{~nm}$ in thickness for individual

* To whom correspondence should be addressed. E-mail: jianglin@ ntu.edu.tw. plates. $^{21,22}$ By ionic exchanging and consequently embedding with various hydrophobic poly(oxypropylene) (POP) amine salts with the molecular weight range from 230 to $5000 \mathrm{M}_{\mathrm{w}}$, the originally hydrophilic clays were consequently converted into organically modified clays with an amphiphilic property ${ }^{23}$ and highly regular basal spacing. It was also found that the amphiphilic clays enabled self-assembly to form orderly structures, for example, the formation of rod-like microstructures at $100-800 \mathrm{~nm}$ in diameter and $2-40 \mu \mathrm{m}$ in length. The ability of self-organization from the naturally occurring clays was reported first time. ${ }^{24}$

To generalize this self-assembling process and the piling mechanism, we use two clay species of different plate dimension for the self-assembly. Both the natural montmorillonite (MMT) and the synthetic fluorinated mica (mica) are similar in primary stack structures, but with different plate sizes and ionic-charge characters. By comparing their morphological changes and process conditions, we propose a unit piling mechanism to account for the clay self-assemblies.

\section{Experimental Section}

Materials. The synthetic fluorinated mica (mica; SOMAS$\left.\mathrm{IF}^{\mathrm{TM}} \mathrm{ME}-100\right)$ with a chemical composition of $\mathrm{Si}$ (26.5 wt \%), $\mathrm{Mg}$ (15.6 wt \%), $\mathrm{Al}(0.2 \mathrm{wt} \%), \mathrm{Na}$ (4.1 wt \%), Fe (0.1 wt \%), $\mathrm{F}(8.8 \mathrm{wt} \%)$ and a cation exchange capacity $(\mathrm{CEC})=1.20$ $\mathrm{meq} / \mathrm{g}$ was obtained from CO-OP Chemical Co. (Japan). Sodium montmorillonite $\left(\mathrm{Na}^{+}-\mathrm{MMT}\right)$, the $\mathrm{Na}^{+}$form of layered smectite clay with a cation-exchange-capacity (CEC) of $1.20 \mathrm{meq} / \mathrm{g}$, was supplied from Nanocor Co. POP-diamines are commercially available under the trade name of Jeffamine amines and were purchased from Huntsman Chemical Co. or Aldrich Chemical Co. The POP2000 diamine is a polyoxypropylene-bis-(2propylamine) of $2000 \mathrm{M}_{\mathrm{w}}$ (i.e., Jeffamine D-2000, amine content $0.98 \mathrm{meq} / \mathrm{g}$ and averaged 33 oxypropylene units in the backbone).

Preparation of POP-amine Intercalated Clays at 1.0 CEC. The POP-amine salts were prepared by treating the POP2000 diamine (12 g, $6.0 \mathrm{mmol})$ with an equivalent amount of 
TABLE 1: XRD $d$ Spacing and Dispersing Properties of the POP-Modified Clays

\begin{tabular}{|c|c|c|c|c|c|c|}
\hline \multirow{2}{*}{$\begin{array}{l}\text { equiv ratio } \\
\text { of POP-salt } \\
\text { to clay CEC }\end{array}$} & \multicolumn{2}{|c|}{$\begin{array}{c}d \text { spacing }(\mathrm{nm}) \text { and } \\
\text { organic fraction } \\
\text { (wt \% in parenthesis) }\end{array}$} & \multicolumn{2}{|c|}{ dispersion (MMT and mica) } & \multicolumn{2}{|c|}{$\begin{array}{l}\text { observation of } \\
\text { self-assemblies from } \\
\text { MMT or mica }\end{array}$} \\
\hline & $\mathrm{MMT}$ & mica & water & toluene & method A & method B \\
\hline pristine & 1.2 & 1.2 & dispersible & aggregate & none & none \\
\hline 0.2 & $1.9(22)$ & $1.5(24)$ & dispersible & aggregate & $\begin{array}{l}\text { rods (from MMT: } 0.1-0.8 \\
\mu \mathrm{m} \text { in width } \\
\text { and } \sim 10 \mu \mathrm{m} \text { in length; } \\
\text { from mica: } \\
0.3-2.0 \mu \mathrm{m} \text { in width and } \\
\sim 30 \mu \mathrm{m} \text { in length) }\end{array}$ & none \\
\hline 0.5 & $2.0(34)$ & $4.0(48)$ & partially aggregate & partially aggregate & rods & none \\
\hline 1.0 & $5.7(63)$ & $4.1(53)$ & aggregate & dispersible & none & $\begin{array}{l}\text { rod-bundles (from mica: } \\
3 \mu \mathrm{m} \text { in width and } \\
\sim 40 \mu \mathrm{min} \text { length) } \\
\text { dendrites (from MMT) }\end{array}$ \\
\hline
\end{tabular}

hydrochloric acid (35 wt \%, $0.63 \mathrm{~g}, 6.0 \mathrm{mmol}$ ) in a separate flask and were added into the fully swelled $\mathrm{Na}^{+}$-mica or $\mathrm{Na}^{+}$MMT (5.0 g, $6.0 \mathrm{meq}$ ) water suspension. The resultant slurry was continuously agitated for $5 \mathrm{~h}$ at $80{ }^{\circ} \mathrm{C}$. The precipitates were collected at ambient temperature, washed thoroughly with toluene/ethanol mixtures, and dried at ambient temperature. The POP-intercalated organoclays with different CEC ratios were prepared by the same procedures.

Preparation of film for Self-assembled POP-mica and MMT. The SEM samples were prepared by taking a portion of the air-dried crude POP-mica and MMT (0.2 CEC) and dispersing it in water at $1 \mathrm{wt} \%$ concentration using an ultrasonic vibrator as the homogenizer until homogeneous. The waterdispersed sample was spread onto a glass plate surface that was subsequently placed in an oven at $80{ }^{\circ} \mathrm{C}$ for $24 \mathrm{~h}$ in order to recover a dried sample for analysis. Both the POP-mica and the MMT (1.0 CEC) were dispersed in toluene in at least 5 wt \% solid content using an ultrasonic vibrator as the homogenizer. The fine dispersion of the organoclays in toluene was slowly poured into the water layer to form a standing two-phase system. A thin film appeared in the toluene/water interface after settling for $1 \mathrm{~h}$. The film was isolated and dried under the condition of $80{ }^{\circ} \mathrm{C}$ for $24 \mathrm{~h}$ for analysis.

Characterization. The interlayer basal spacing, or $d$ spacing, was analyzed using an X-ray powder diffractometer (Schimadzu SD-D1 using a $\mathrm{Cu}$ target at $35 \mathrm{kV}, 30 \mathrm{~mA}$ ) with a scanning rate of $2 \% \mathrm{~min}$ from $2 \theta=2^{\circ}$ to $2 \theta=14^{\circ}$. The organoclays generally exhibit a series of multiple peaks with a pattern following the Bragg's equation. The value of $d$ spacing for $n$ $=1$ was calculated from the observed values of $n=2,3,4$, etc, according to the Bragg's equation $(n \lambda=2 d \sin \theta)$. The samples with the high $d$ spacing generally have a high regularity

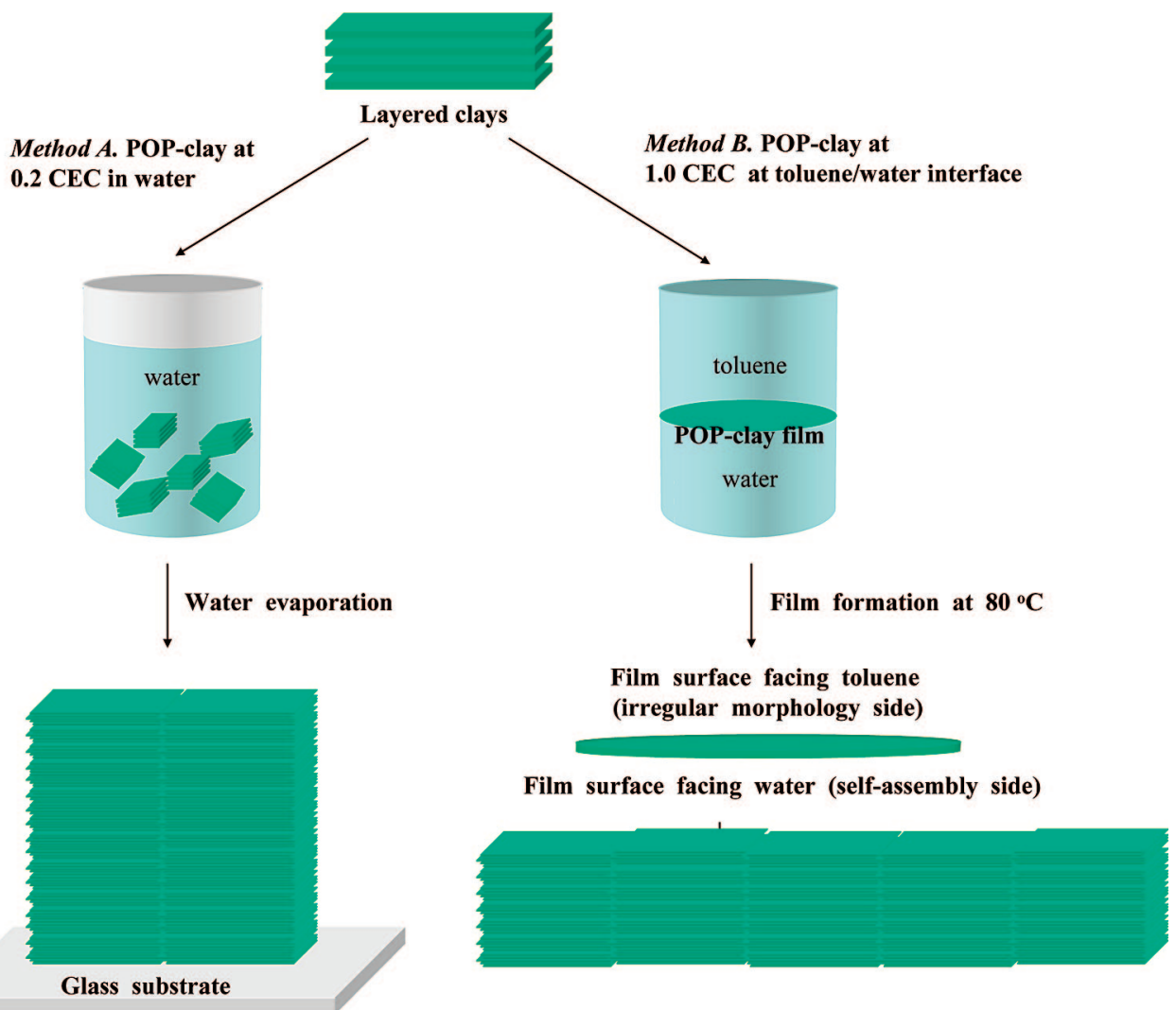

Figure 1. Conceptual diagram of POP-clay self-assembling procedures. (A) Direct water-evaporation method: POP-clay (0.2 CEC intercalation) dispersed in water and then evaporated to dryness; (B) toluene/water interfacial film method: POP-clay (1.0 CEC) dispersed in toluene, adding water phase and standing for a film formation. 

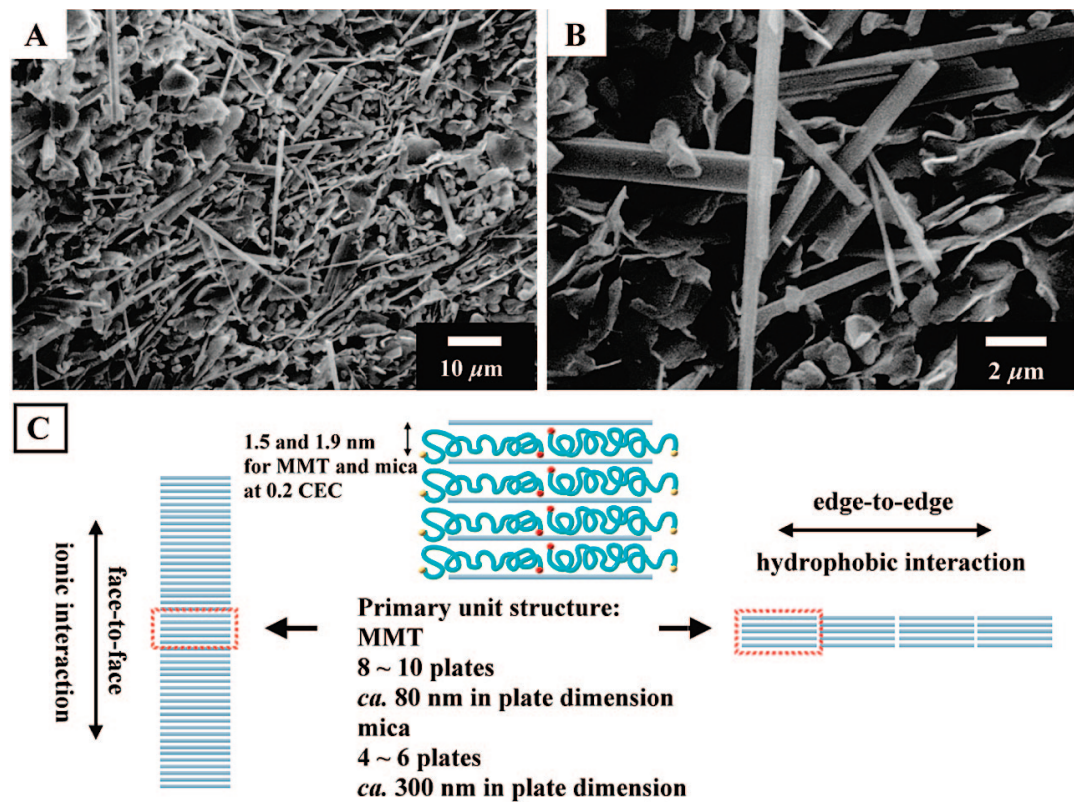

Figure 2. SEM images of rod-like microstructures from the self-assembling of the POP-mica organoclays (at 0.2 equiv of POP-intercalation to clay CEC), by the direct water-evaporation method. (A) some rod-like arrays with dimensions of $0.3-2.0 \mu \mathrm{m}$ in width and 5-30 $\mu \mathrm{m}$ in length; (B) the magnified rod-like morphology; (C) conceptual explanation for the formation of these rod-like arrays via two possible directions of piling the primary clay units (represented by a five-plate-stack in the center drawing).

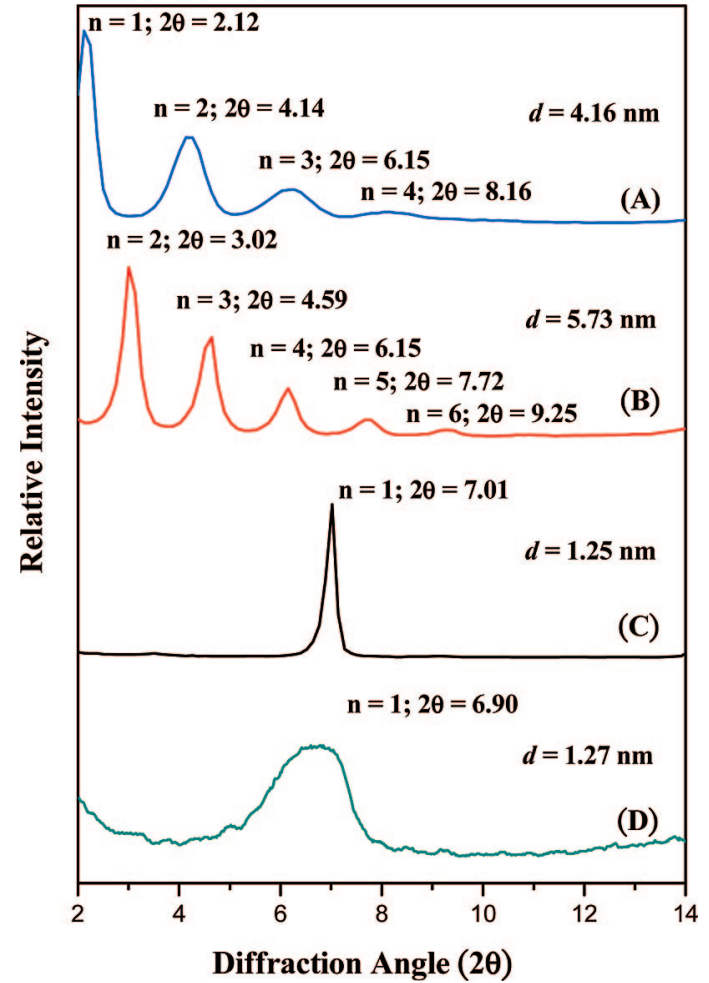

Figure 3. XRD patterns of (A) POP-mica (1.0 CEC); (B) POP-MMT (1.0 CEC); (C) mica; and (D) MMT.

of Bragg's patterns, which permit an accurate estimation of $n$ $=1 d$ spacing. The organic fractions were estimated using a thermal gravimetric analyzer (TGA, Perkin-Elmer Pyris 1) with a temperature gradient that ramped from room temperature to $800{ }^{\circ} \mathrm{C}$ at a rate of $10^{\circ} \mathrm{C} \mathrm{min}-1$. Scanning electron microscopy (SEM, TOPCON ABT-150S operated at $15 \mathrm{kV}$ ) and fieldemission scanning electron microscopy (FE-SEM, JEOL JSM$6700 \mathrm{~F}$ operated at $15 \mathrm{kV}$ ) were used to examine the surface morphologies. The surface element analysis was performed by energy dispersive X-ray spectroscopy (EDS, OXFORD INCA
ENERGY 400). Transmission electron microscopy (TEM) was performed on a Zeiss EM 902A operated at $80 \mathrm{kV}$. Tappingmode atomic force microscopy (TM-AFM, Seiko SPI3800N, Series SPA-400HV; cantilever type: SI-DF20, $f=139 \mathrm{kHz}$, spring constant $=16 \mathrm{~N} \mathrm{~m}^{-1}$ ) was also used to characterize the surface morphology.

\section{Results and Discussion}

The structure of synthetic fluorinated mica is well-defined ${ }^{21,23,25}$ and is known to have a high aspect-ratio with a large plate dimension of (averaged) $300-500 \mathrm{~nm}$ (4-6 plates in one primary stack), much larger than that of the $80-100 \mathrm{~nm}$ dimension in the $\mathrm{Na}^{+}$-MMT units $(8-10$ plate stack) and commonly $1 \mathrm{~nm}$ in plate thickness. Both clays have a similar cation-exchange-capacity $(\mathrm{CEC}=120 \mathrm{meq} / 100 \mathrm{~g})$. With the POP-amine embeded into the MMT layered structure, the resultant clay hybrids were expanded in basal spacing and exhibited an amphiphilic property. ${ }^{23}$ As shown in Table 1, the embedding of increasing amounts of POP2000 may totally convert the hydrophilic clays to be dispersible in toluene. With the POP intercalation at 0.2 CEC, or $20 \%$ of clay exchanging capacity, the modified MMT and mica hybrids were still dispersible in water but showed a surfactant property of lowering the surface tension (water/air) from 70 to $41 \mathrm{mN} / \mathrm{m}$ at $1 \mathrm{wt} \%$.

Subsequently, it was found that the POP-modified MMT at $0.2 \mathrm{CEC}$ could self-assemble to form the lengthy-rod morphology ${ }^{24}$ without any surfactant templates. Experimentally, the self-assembly was performed by simply dispersing the organoclays in water at the concentration of $1 \mathrm{wt} \%$ and then subjecting it to evaporation until dryness at $80{ }^{\circ} \mathrm{C}$ for $24 \mathrm{~h}$ (Figure 1A). The resulting material was characterized as rod-like arrays in high uniformity with an average dimension of $0.1-0.8 \mu \mathrm{m}$ in width and $2-10 \mu \mathrm{m}$ in length. By comparison, the analogous POP-mica hybrid at $0.2 \mathrm{CEC}$ also enabled self-assembly, but in a larger-size rod morphology $(0.3-2.0 \mu \mathrm{m}$ in width and 5-30 $\mu \mathrm{m}$ in length), as shown in Figure 2, panels $\mathrm{A}$ and $\mathrm{B}$. With the increasing POP 

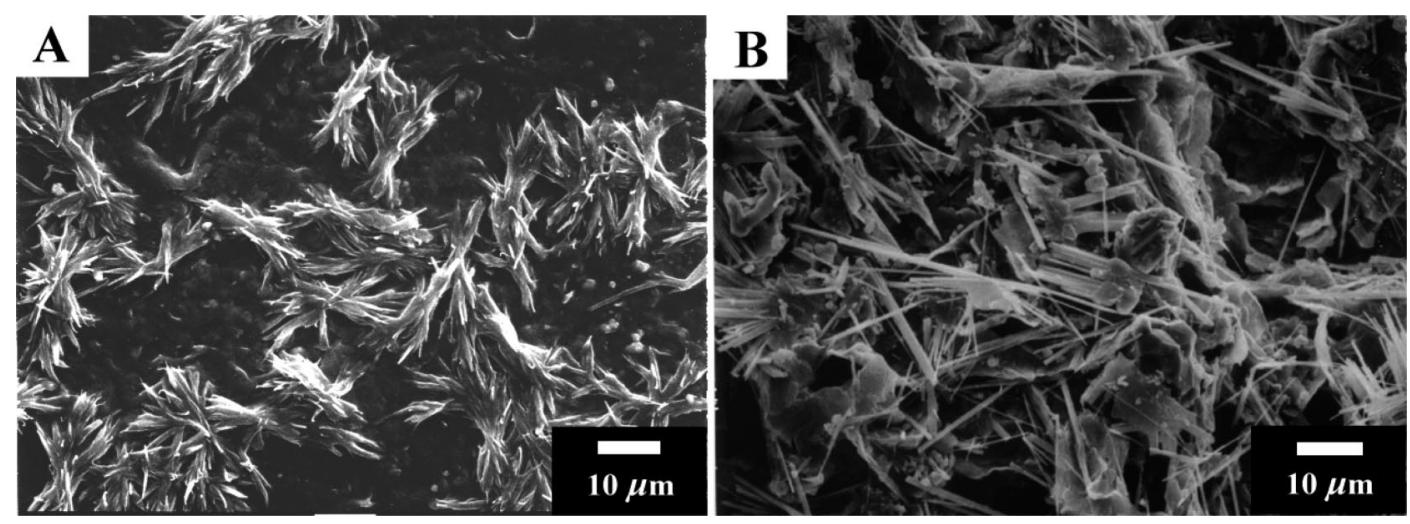

Figure 4. SEM micrographs of a film surface, self-assembled from POP-clay (1.0 CEC) at the toluene/water surface. (A) dendrites from POPMMT; (B) rods at the dimension of $10-30 \mu \mathrm{m}$ in length and $0.2-0.5 \mu \mathrm{m}$ in diameter from POP-mica.

intercalation at $0.5 \mathrm{CEC}$, the POP-MMT and POP-mica both exhibited self-assembly in a less orderly structure. In contrast, the POP at 1.0 CEC rendered the organoclays nondispersible in water and failed to form any regular morphology (Figure $\mathrm{S} 1$, comparing A, B, and C). The rod-like crystals were shown by the X-ray diffraction to have a similar $d$ spacing to the primary units $(5.7 \mathrm{~nm}$ for MMT and $4.1 \mathrm{~nm}$ for mica, respectively). Previously, the TEM had revealed the primary units that were comprised of an averaged $8-10$ plate layers for MMT and 4-6 plate layers for mica. ${ }^{20,23}$ The result implied that the self-assemblies were actually derived from the piling of the primary MMT and mica unit structures. The fundamental clay dimension of POP-MMT (5.7 nm XRD $d$ spacing) has an average height of $40-52 \mathrm{~nm}$ from the topographical image of AFM analysis (Figure S2, for the POP-MMT primary unit). The approximate calculation amounts to $52 \mathrm{~nm}(5.7 \mathrm{~nm} d$ spacing times the height of $8-10$ platelets in a stack), and the number of 8-10 platelets in a stack as the primary MMT unit was consistent with the previous observation. ${ }^{20,26}$

It is noteworthy, that these POP-clay units have a general series of XRD Bragg's peaks, indicating the regularity of repetitive distance between the neighboring plates (Figure 3). The piling mechanism could involve two possible directions from the primary units to orientate into the lengthy rods. The conceptual diagram in Figure 2C illustrates the unit alignment through POP edge-to-edge or plate face-to-face orientation to form the lengthy arrays. The embedded POP-amines in the layers are responsible for the edge-to-edge directional growth, whereas the flat plates are responsible for another direction into rod morphology. Presumably, the plate face-to-face piling is derived from their surface charge attraction. The preference of the two different directional growths will eventually dictate the length and shape of rods or other morphologies.

The primary unit structures of the POP-intercalated clays generally consist of silicate plates and alternating layers of POP organics in the interlayer space, with the amount ranging from $20 \mathrm{wt} \%$ (in the case of 0.2 CEC intercalation) up to 50-60 wt $\%$ at 1.0 CEC. The amount of the hydrophobic POP largely dictates their dispersion ability in water or toluene, as shown in Table 1. Among these POP-clay hybrids, the particular 1.0 CEC sample is hydrophobic, is dispersible in toluene rather than in water, and is able to form a thin film at the toluene/water interface. In Figure 1, two different procedures, the direct waterevaporation (method $\mathrm{A}$ ) and the film formation at the toluene/ water interface (method B), are described. From method B, the film surfaces of both sides, facing water- or toluene-side during the formation, appeared to have different morphologies under
SEM examination (Supporting Information Figure S3). Only the surface of the facing water phase grew into the rod-like crystals. Elemental analyses on this film side by EDS showed a rich content in a carbon-to-silicon ratio of $13.95 / 42.47$, in contrast to the toluene side of 37.51/18.72 (Supporting Information Figure S4). The apparently different compositions on the film surfaces indicate a possible unit migration during the selfassembling process. The water surface promotes the orientation of hydrophilic silicate plates into lengthy rods. For generating the rod-like morphologies, the POP-MMT at $1.0 \mathrm{CEC}$, in comparison with the POP-mica at 1.0 CEC, tended to form the shorter rods but propagated into different directional dendrites, as observed in Figure 4A. Because the POP-organics are considered to be inherently amorphous and flexible materials, the main driving force for the unit piling could come from the flat plate geometric shape in favor of face-to-face arrangement. With a large plate size, the POP-mica units may have a strong tendency for piling into lengthy rods with the dimension of $10-40 \mu \mathrm{m}$ in length and $0.2-0.5 \mu \mathrm{m}$ in width (Figure $4 \mathrm{~B}$ ). The self-assembled rods derived from the mica appeared to be straight and lengthy in shape, whereas the rods from the POPMMT are less straight but in a dendritic shape. Hence, the plate geometric shape appears to dominate the piling process by which the wider dimensional plate disk could significantly lead to the lengthy rod formation. With the smaller disk, the plate-shape directing effect is less intensive and tends to deviate into different directions, or a dendrite formation.

To further understand the formation of these microstructures, we examined the individual microstructures using AFM and TEM in a detailed examination. The individual rods were isolated using an ultrasonic vibrator to peel off pieces from the scaffold of the microstructure and placed them on the copper grid holder. One of the rods, approximately $15 \mu \mathrm{m}$ in length and $200 \mathrm{~nm}$ in diameter (Figure 5, panels A and B), and another representative rod, at $5 \mu \mathrm{m}$ in length and $45 \mathrm{~nm}$ in diameter, were examined by TEM (Figure 5, panels $\mathrm{C}$ and D), revealing the detailed structure in which the edge-to-edge alignment is more likely than the face-to-face unit piling from the texture or detailed lines of these micrographs. This rod structure was selfpiled from the primary units of averaged 4-6 silicate layers and POP-embedded $4.1 \mathrm{~nm} d$ spacing with the plate dimension of 300-500 nm (one representative piling shown in the inset of Figure 5D). In the AFM image and measurement (Figure $5 \mathrm{E}$ ), the single rod was characterized to be $200 \mathrm{~nm}$ in height and $500 \mathrm{~nm}$ in width. The magnified micrograph in Figure 5F vividly shows the lines of propagation into lengthy rods that more than likely matches the unit dimension of edge-to-edge alignment rather than the face-to-face piling. The morphology 

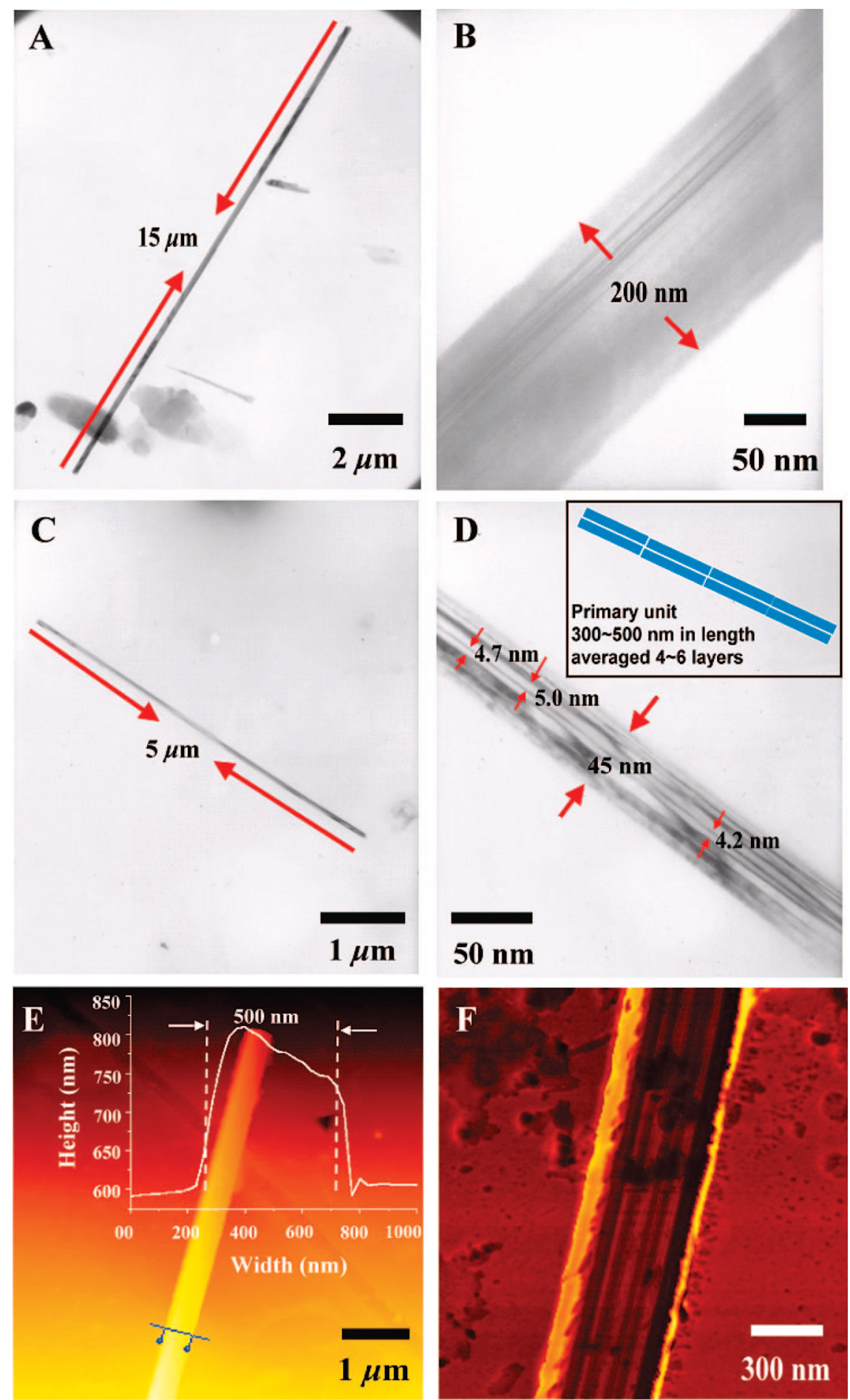

Figure 5. Morphologies of three representative POP-mica $(1.0 \mathrm{CEC})$ rods, isolated from the film surface on water side by using an ultrasonic vibrator to break up from the film surface and placed on the copper grid holder: (A and B) TEM micrographs of the individual rod at $15 \mu \mathrm{m}$ in length and $200 \mathrm{~nm}$ in diameter; (C and D) TEM of the rod at $5 \mu \mathrm{m}$ in length and $45 \mathrm{~nm}$ in diameter; the inset represents the piling of eight primary clay units with the analysis of X-ray $d$ spacing at $4.1 \mathrm{~nm}$. (E and F) AFM topographical image of another rod at $200 \mathrm{~nm}$ in height and $500 \mathrm{~nm}$ in width, and showing the texture of rod formation similar to (B and D).

of this single rod appears to be constructed with several straight lines in parallel. Furthermore, during the formation of single rods in the self-piling process, the secondary structure of rods were formed and aligned into bundles or large rods. As shown is one of such bundles at $40 \mu \mathrm{m}$ in length and $3 \mu \mathrm{m}$ in width (Figure 6A). The width of individual rods was not uniform on the detailed observation by AFM (Figure 6B), perhaps due to the polydispersed nature of different mica plate units. On the basis of the SEM micrographs (Figure 6, panels C and D), the observation of initiatory position for the rod-bundles may imply the formation of the secondary and tertiary structures through a hierarchically growing from all clay units in a simultaneous manner. For the primary structure of mica stacks at 300-500 $\mathrm{nm}$ in platelet width and $20 \mathrm{~nm}$ in height (one stack of 4-6 layers $\times 4.1 \mathrm{~nm}$ spacing by XRD analysis), an individual rod is constituted of $10-25$ primary clay stacks by face-to-face piling $(0.3-0.5 \mu \mathrm{m}$ in width), with an average of 100 building blocks piling in another direction of edge-to-edge $(30-40 \mu \mathrm{m}$ 

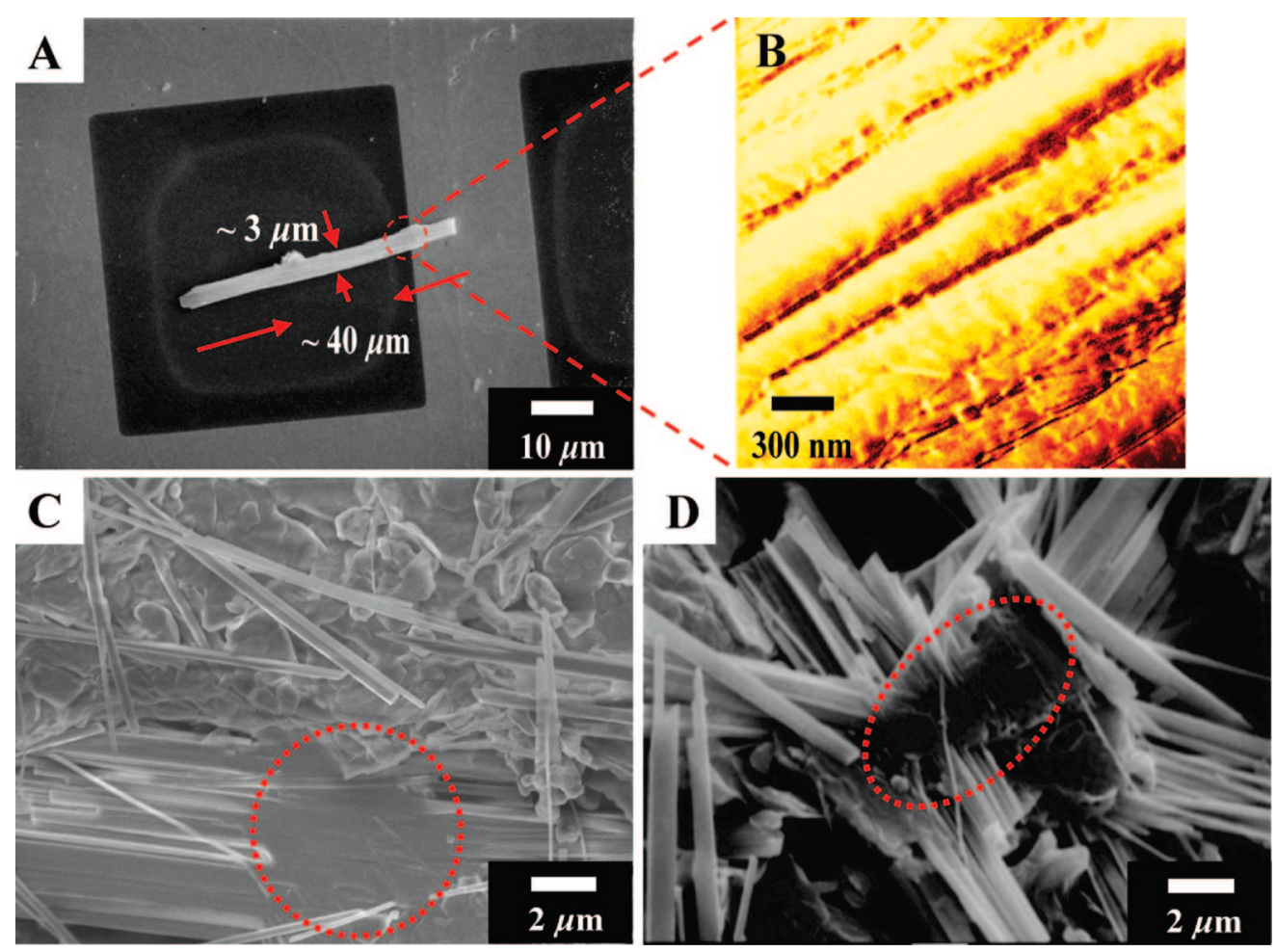

Figure 6. Micrographs of rod-bundles. (A) A rod-bundle on the TEM copper-grid showing the bundle dimension at $40 \mu \mathrm{m}$ in length and $3 \mu \mathrm{m}$ in width; (B) AFM (phase image) of the rod-bundle; (C and D) SEM images of mixed single-rods and rod-bundles.

in length). This self-assembly occurred only in the toluene/water interface, initiated by the primary stack piling in the edge-toedge direction. The isolated single rods having a width of 0.3 $\mu \mathrm{m}$ and the rod-bundle having width of $3 \mu \mathrm{m}$ are two representative examples. Based on the observed dimension of one circle, the rigid rod morphology under SEM could be composed of approximately 100 small rods.

It is noted that the hierarchical growth of primary clay units into rod-bundles is not observed in the naturally mineral environment. The introduction of the embedded POP organics plays an important role for directing this fast self-assembling process. The uniqueness of POP interaction for the self-assembly is further supported by using the organic-free or "pure" plates for self-piling. We have isolated the organic-free synthetic fluorinated mica plates from the sequential polyamine exfoliation and extraction process. ${ }^{27,28}$ The isolation of pure synthetic fluorinated mica plates, behaving as hydrophilic and forming a suspension in water, allowed us to observe the phenomenon of plate piling. In Supporting Information Figure S5, the thin plates are shown to have the same ability to self-piling into rods but in different morphological microstructures. By comparison, the presence of POP organics allows the control of plate piling direction and consequently the versatility of the self-assembled morphologies.

\section{Conclusion}

The hydrophobic POP intercalated clays including MMT and mica enable self-assembly into various microarrays such as dendrites, rods, and rod-bundles. The geometric shape of lamellar clays is an important factor for directing the selfassembly. In particular, the mica clay with a high aspect-ratio shape could self-pile to form hierarchical structures of rods and secondary rod-bundles. The process of forming microstructures with high regularity in plate spacing may be potentially useful for fabricating new nanomaterials for applications such as photonic crystals. ${ }^{29,30}$

Acknowledgment. This work was financially supported by the National Science Council (NSC) of Taiwan and partially by the Ministry of Economic Affairs, Taiwan.

Supporting Information Available: This material is available free of charge via the Internet at http://pubs.acs.org.

\section{References and Notes} 1312 .

(1) Whitesides, G. M.; Mathias, J. P.; Seto, C. T. Science 1991, 254,

(2) Bihannic, I.; Michot, L. J.; Lartiges, B. S.; Vantelon, D.; Labille, J.; Thomas, F.; Susini, J.; Salome, M.; Fayard, B. Langmuir 2001, 17, 4144.

(3) Heuer, A. H.; Fink, D. J.; Laraia, V. J.; Arias, J. L.; Calvert, P. D.; Kendall, K.; Messing, G. L.; Blackwell, J.; Rieke, P. C.; Thompson, D. H.; Wheeler, A. P.; Veis, A.; Caplan, A. I. Science 1992, 255, 1098.

(4) Mann, S. Nature 1993, 365, 499.

(5) Tang, Z.; Kotov, N. A.; Mahonov, S.; Ozturk, B. Nat. Mater. 2003, $2,413$.

(6) Kagan, C. R.; Mitzi, D. B.; Dimitrakopoulos, C. D. Science 1999, 286,945

(7) Nawa, N.; Baba, R.; Nakabayashi, S.; Dushkin, C. Nano Lett. 2003, 3, 293.

(8) Zakhidov, A. A.; Baughman, R. H.; Iqbal, Z.; Cui, C.; Khayrullin, I.; Dantas, S. O.; Marti, J.; Ralchenko, V. G. Science 1998, $282,897$.

(9) Wang, C.; Shim, M.; Guyot-Sionnest, P. Science 2001, 291, 2390.

(10) Xia, Y.; Yang, P.; Sun, Y.; Wu, Y.; Mayers, B.; Gabtes, B.; Yin, Y.; Kim, F.; Yan, H. Adv. Mater. 2003, 15, 353.

(11) Hartgerink, J. D.; Beniash, E.; Stupp, S. I. Science 2001, 294, 1684.

(12) Jenekhe, S. A.; Chen, X. L. Science 1999, 283, 372.

(13) Li, M.; Schnalbegger, H.; Mann, S. Nature 1999, 402, 393.

(14) Pinnavaia, T. J. Science 1983, 220, 365.

(15) Giannelis, E. P. Adv. Mater. 1996, 8, 29.

(16) Ray, S. S.; Okamoto, M. Prog. Polym. Sci. 2003, 28, 1539.

(17) Theng, B. K. G. The Chemistry of Clay-Organic Reactions; John Wiley \& Sons: New York, 1974.

(18) Gabriel, J. P.; Davidson, P. Adv. Mater. 2000, 12, 9.

(19) Lin, J. J.; Cheng, I. J.; Wang, R.; Lee, R. J. Macromolecules 2001, 34,8832 . 
(20) Chou, C. C.; Shieu, F. S.; Lin, J. J. Macromolecules 2003, 36, 2187.

(21) Akelah, A.; Moet, A. J. Appl. Polym. Sci.: Appl. Polym. Symp. 1994, 55, 153

(22) Usuki, A.; Hasegawa, N.; Kadoura, H.; Okamoto, T. Nano Lett. 2001, 1,271

(23) Lin, J. J.; Chen, Y. M. Langmuir 2004, 20, 4261.

(24) Lin, J. J.; Chou, C. C.; Lin, J. L. Macromol. Rapid Commun. 2004, 25,1109 .

(25) McNally, T.; Murphy, W. R.; Lew, C. Y.; Turner, R. J.; Brennan, G. P. Polymer 2003, 44, 2761.
(26) Lin, J. J.; Wei, J. C.; Juang, T. Y.; Tsai, W. C. Langmuir 2007, 23, 1995.

(27) Lin, J. J.; Chu, C. C.; Chiang, M. L.; Tsai, W. C. J. Phys. Chem. B 2006, 110, 18115.

(28) Lin, J. J.; Chu, C. C.; Chiang, M. L.; Tsai, W. C. Adv. Mater. 2006, 18,3248 .

(29) Norris, D. J.; Arlinghaus, E. G.; Meng, L.; Heiny, R.; Scriven, L. E. Adv. Mater. 2004, 16, 1393.

(30) Imhof, A.; Pine, D. J. Nature 1997, 389, 948.

JP801733A 